\title{
Factors Influencing Intention to Use Fitness Trackers: A Case Study on Thais' Living in Bangkok
}

Submitted 05/01/20, $1^{\text {st }}$ revision 09/02/20, $2^{\text {nd }}$ revision 30/03/20, accepted 16/05/20

\begin{abstract}
Rawin Vongurai ${ }^{1}$
Abstract:

Purpose: In the booming health care industry in Thailand, fitness tracker is a rapidly growing wearable device trend across globe, which has gained popularity in Thailand, especially in Bangkok Metropolitan Area. The crucial objective of this study is to identify the influencing factors towards the intention to use fitness trackers among the Thai's living in Bangkok.

Design/Methodology/Approach: The researcher developed the conceptual framework from a technology acceptance model (TAM) theory. An online survey was constructed and distributed through several social media platforms. Subsequently, the amount of reliable responses were 633. Confirmatory Factor Analysis (CFA) along with Structural Equation Model (SEM) were key methods to verify the validity and reliability of the model and to examine the influence among variables.

Findings: Consequently, the result revealed significant effect between perceived usefulness and attitude towards the intention to use fitness trackers. However, there are no significant effect between cost and the intention to use fitness trackers. Moreover, the result confirmed that affective quality and relative advantage has a strong direct effect on perceived usefulness whilst the 'anywhere-anytime' concept of mobility as well as directly affecting perceived ease of use.

Practical Implications: Further study could be enhanced by incorporating more some social value towards the model because it is a weakness of TAM.

Originality/Value: This study creates value for the marketers of fitness tracker to make a clear statement on the differences of product performance and features comparing to the prior or existing one in the market (relative advantage).
\end{abstract}

Keywords: Affective quality, intention to use fitness trackers, perceived ease of use, perceived usefulness, relative advantage.

JEL Code: M15, M31.

Paper Type: Research Paper.

${ }^{1}$ Ph.D., Department of Innovative Technology Management, Graduate School of Business, Assumption University of Thailand, e-mail: rawinvng@au.edu 


\section{Introduction}

Fitness tracker is a part of wearable devices which have been growing rapidly in recent years and also continued to have bright growth prospect. It allows people to easily track their health effectively throughout the day and improve their fitness level more efficiently than what precursors. Moreover, the acceptance of data from healthcare communities in relation to the wearables is also developed numerously. The very first activity trackers known as fitness trackers was caught as a mainstream attention in 2008, when a brand named 'Fitbit' debut a clip-on device in the U.S. Since then, many tech companies tried to compete in the field with various specific activity-monitoring features largely dedicated to heart rate monitoring, calorie calculation, counting steps, running and tracking sleep quality. Subsequently, people also considered fitness tracker as a good companion to help them loss weight. According to its ability to visualized health to an index and show a lot of information in a user-friendly platform, it acts as a motivator to keep users to stay in good shape and consciously aware or health along the day. Lately, various brands of fitness trackers also provide a community for users to create engagement and help them achieve their personal goal through coaching.

According to Gartner (2018), wearable devices are expected to deliver an outstanding growth rate of 26.3\% CAGR from 140 Million units shipment in 2017 to 453 Million units in 2022. Obviously, fitness tracker is one of the potential contributors to this huge market growth of wearable devices in the future. Meanwhile in Thailand, 'running' is recognized as a famous sport and activity that stands out among various kinds of sports, considering as one of those easy-attempt workouts; low upfront cost and can be a great kind of group activity. Unsurprisingly, number of Thailand runners had rose significantly from 5.8 Million in 2002 to 15 Million in 2017 (Thai Health Promotion Foundation, 2018) representing 6.5\% growth CAGR in the past 15 years.

Thanks to "Seven something" a movie by GTH - local movie production house, which helped encouraging people to run more in 2015. Moreover, in 2016-17, Thailand had a very successful initiative from a project named in Thai as "Kao Kon La Kao", which was led by Thailand artist Artiwara Kongmalai with an aim to help local hospitals having more medical equipment by donating along their long distance running campaign from South to North region totaled about 2,215 km. As a result, running is a kind of easy exercise that came up into Thai people's mindset in which everyone can do as a preventive measurement for their health and reduce cost related to medical in future. As a result, this study is focused to assess related factors towards purchase intention of fitness trackers in Bangkok Metropolitan area.

\section{Literature Review}

\subsection{Technology Acceptance Model}


Davis (1986) defined Technology Acceptance Model (TAM) which helped to understand and predict the usage behavior of computer technology. Furthermore, TAM was also explained through another theory namely, Theory of Reasoned Action (TRA), which was developed by Fishbein and Ajzen in 1975 focusing on social psychology. However, TRA mainly focus on explaining people's behavior through their intentions, in general, human behavior. To simplify, TRA has been using individual attitude and social norms in order to explain why people approve or disapprove certain behavior (Figure 1).

Subsequently, TAM, which intended further adoption to elaborate the information determinants and communication technologies (ICT), which explained general and capable user behavior based on a broad basis of end-users. In fact, TAM was developed initially for system characteristics and assumed that ICT are used mainly in organization only to enhance worker's efficiency. As such, further revision has been made on TAM in order to tailor made a particular context of such analyzed technology because previously TAM did not integrate 'non-organization' settings which nowadays being heavily influence user's decision related to ICT. However, TAM remained one of the most popular utilized theory to study end-user acceptance of ICT. While dividing TRA's 'attitude' into two variables perceived usefulness (PU) and perceived ease of use (PE) are key psychological user determinants towards attitude (Figure 2).

Figure 1. Theory of Reasoned Action (TRA)

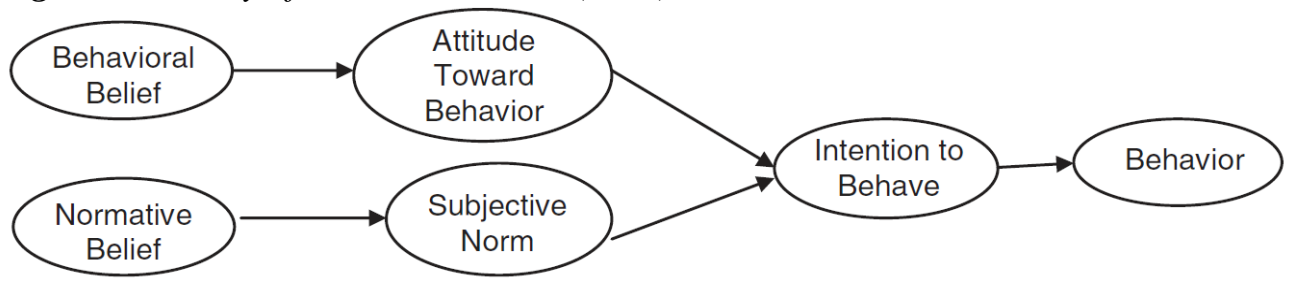

Source: Fishbein and Ajzen (1975).

Figure 2. Technology Acceptance Model (TAM)

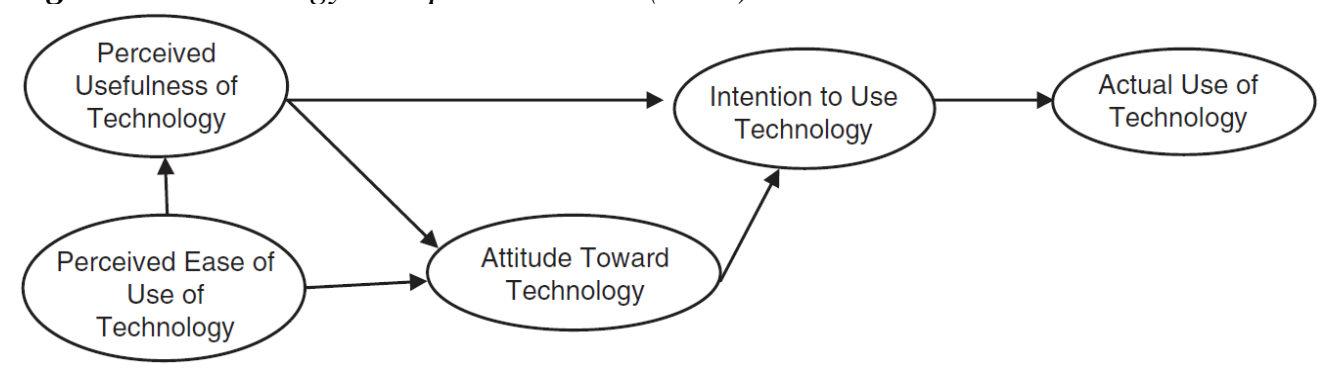

Source: Davis (1986).

Affective Quality (AQ) refers to the capability to cause and emotion to the users. It is important for users to have a positive psychological trait against the products in order 
to influence the intention to purchase, which mostly through the usefulness that user can find on fitness trackers both functional and experiential perspective (Kurosu and Kashimura, 1995). In addition, the look and feel also play an essential role in giving an idea of its capability and innovation (Seva, Duh and Helander, 2007).

Relative Advantage (RA) refers to the betterment of one fitness tracker over another or the current/previous versions. The superiority, premium and value added are what potential adopters or buyers want to know the level of which a new service or product has good performance over the existing ones (Bennett and Bennett, 2003). Therefore, the higher the relative advantage, the more likelihood of the users to change from their current practice or to purchase of new products (Rogers, 1995). In addition, products must also clearly indicate consumers with both incremental benefits (usefulness) and costs compared to current or prior technology or practice.

Mobility (M) refers to the "anywhere-anytime" characteristic of fitness trackers. The sense that make users believe that the fitness trackers can be carried with them anywhere during the activity they would like to perform is an essential factor (Kynaslahti, 2003). Note that most of the fitness trackers are considered to have less to near zero portable cost for users easily attached or binding with user's body parts.

Availability (AV), as per Webster's dictionary is "the quality of being present or ready for immediate use". For fitness trackers, activities' information and data must be simultaneously synced and translated in to a user-friendly interface for the users in real time to provide a user live best experience and benefit (Shin, 2012). Thus, both mobility and availability will help enhance and support more perceived east of use.

Perceived Usefulness (PU) is a stage when customers believe that fitness trackers can improve in doing some task or make the work efficient. Hence, it is likely to have a positive relationship in between perceived usefulness and intention to use (Pfeffer, 1982; Schein, 1980; Vroom, 1964). In addition, it can also help user to determine how value it is in terms of utility level. In other words, the degree of utilization that user believe they can utilize the fitness tracker (Davis, 1989).

Perceived Ease of use (PE) is identified by how easy it is to use, or in other words, whether any additional cost/action is associated or not. As such, if the product or service claimed to have high perceived ease of use, it should require none or near zero effort for one to use the particular product or service, in other words "Free of effort" (Radner and Rothschild, 1975). For fitness tracker, perceived ease of use is also referred to its user-friendly interface and function that are easily accessible. Despite its various functional ability for multi-tasking, fitness tracker can be attached or bind with each user with little effort. The more easily one require to learn, understand and operate the fitness tracker guide through further perceived ease of use which ultimately help increase attitude and perceived usefulness of the users' towards fitness tracker. 
Attitude (A) are composed from knowledge, emotion and action. It requires knowledge in the process to gradually form emotions towards something whether it is positive or negative, then it will lead to the action towards that particular products or services (Kim and Shin, 2015), which was supported by Britt (1966) in terms of consumer behavior intention. As such, it is an effective way to gain the insights and allow us to predict consumer's behavior. To simplify, attitude represents the degree to which a user has positive or negative understanding or perception towards the use of technology (Fishbein and Ajzen, 1975). The more positive attitude towards fitness trackers will help increase the chance of users to purchase it (Kabayadi and Gupta, 2011; Lorenzo-Romero, Constantinides and Alarcon-del-Amo, 2011; Oyedele and Minor, 2011; Zorn, Jarvis and Bellman, 2010).

Subcultural Appeal (SA) is something that may originate from some beliefs or practices that have been inherited from generation to generation. It can influence people to believe in something that might have no scientific reason and contrast to most of the people (Elder, 1985). Added to such, it can also be defined as a knowledge or commodities that help differentiate anyone from the group of people (Thornton, 1997). In the meantime, fitness trackers are in vogue in a niche group of people, thus, it can help communicate user's unique belief and characteristics to other group of people surrounding them.

Cost (C) is basically the monetary value or items an individual has to pay in order to obtain fitness trackers (Kotler, 2000). If the price is too high compared to the product's value, it can reduce the probability of the purchase intention. Previous research (Luarn and Lin, 2005) proved that perceived cost has been restricted from user's purchase intention. As such, there is an inverse relationship between price and purchase intention. In other words, price is what customers pay, but value is what customers will receive. When the value and price is not aligned or fair in user's perspective, they will likely to neglect the purchase at last. However, there is an exception, when price doesn't negatively correlate with the purchase intention of the product or services. It is the concept of price-inelasticity (Alfred, 1992). If the products or services are having high uniqueness or newly innovative technologies, price must be set according to its positioning in order to create brand value. Therefore, our objective is to identify the factors influencing intention to use fitness trackers in Bangkok Metropolitan area.

\section{Research Framework}

To overture, researcher has been reviewing previous researches that related to intention to use of information technology products and looking for a suitable theoretical framework. Afterwards, the conceptual framework "An acceptance model for smart watches: Implications for the adoption of future wearable technology" (Kim and Shin, 2015) had been adopted to use in this research. While the mentioned study was mainly focused to explore key psychological attributes of smartwatch adoption via affective quality (AQ), relative advantage (RA), mobility (M), 
availability (AV) and subcultural appeal (SA). Furthermore, it also constructed an extended technology acceptance model (TAM) integrating the findings into the original TAM constructs. TAM (Davis, 1986) is popularized in forecasting how individual adopt and voluntarily use technology which was adopted from a popular theory of reasoned action (TRA) (Fishbein and Ajzen, 1975). As such, the conceptual framework consists of 10 variables (Figure 3) with 11 hypotheses.

Figure 3. Conceptual Framework

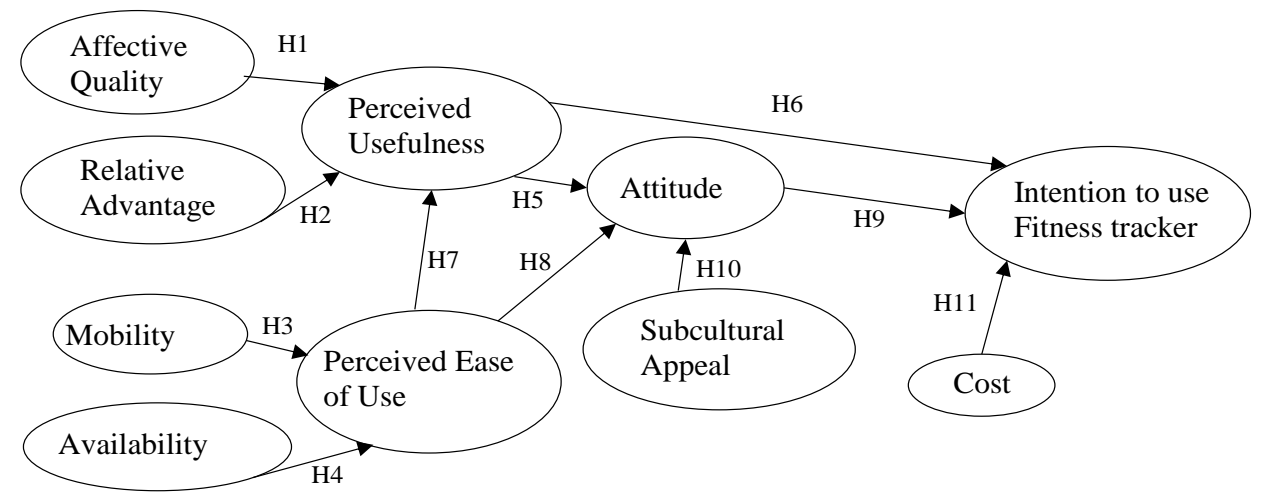

Source: Author.

$H_{1}$ : Affective Quality has a significantly direct impact on Perceived Usefulness.

$\mathrm{H}_{2}$ : Relative Advantage has a significantly direct impact on Perceived Usefulness.

$\mathrm{H}_{3}$ : Mobility has a significantly direct impact on Perceived Ease of Use.

$\mathrm{H}_{4}$ : Availability has a significantly direct impact on Perceived Ease of Use.

$H_{5}$ : Perceived Usefulness has a significantly direct impact on Attitude.

$H_{6}:$ Perceived Usefulness has a significantly direct impact on Intention to use.

$H_{7}$ : Perceived Ease of Use has a significantly direct impact on Perceived Usefulness.

$H_{8}$ : Perceived Ease of Use has a significantly direct impact on Attitude.

$H_{9}$ : Attitude has a significantly direct impact on Intention to Use.

$H_{10}$ : Subcultural Appeal has a significantly direct impact on Attitude.

$H_{11}$ : Cost has a significantly direct impact on Intention to Use.

\section{Research Methodology}

An online survey was designed and distributed in order to assess the target group and proposed factors that intention to use of fitness tracker. Generally, the research was also based on a quantitative approach with people living in Bangkok Metropolitan Area who have experienced fitness trackers are being focused. The survey was basically divided into three parts including a couple of screening questions, a fivepoints Likert scale questions and some demographic questions. Basically, the respondents who has passed the screening question were further asked to submit their response on a five-point Likert scale ranked from "1-strongly disagree" to "5- 
strongly agree". Finally, 633 fitness tracker users also asked to fill in their demographic details such as gender, age, income level and so on.

The online survey was initially distributed to 30 respondents as a pilot group in order to test the reliability using Cronbach's alpha analysis. The participants were those who are currently living in Bangkok Metropolitan Area and had experienced using fitness trackers. The researcher used non-probability sampling method of convenience sampling technique to collect data totaling 633 respondents. The data were analyzed by using IBM SPSS statistics for Windows, version 24 and AMOS 18.0 software. Added to such, Confirmatory Factor Analysis (CFA) was further conducted for the convergent and discriminant validity test of the results to confirm the fit of this research's conceptual framework. The measurement model fit was analyzed in order to test the overall fit with the data and further ensure the model's validity and reliability. Lastly, the impact among variables were examined through the Structural Equation Model (SEM).

\subsection{Population and Sample Size}

Regarding to structural equation model (SEM), the target population and number of factors should be considered cooperatively in order to provide a stable solution. The greater number of factors will lead to the larger size according to Hair, Black, Babin and Anderson (2010). Thus, it resulted in an appropriate sample size for ten variables having a minimum of 500 respondents. While the study is focus on the respondents living in Bangkok metropolitan area and had experienced using fitness trackers. Eventually, there were 671 participants from different background, nevertheless, 38 participants did not pass the screening questions. After all, there were 633 respondents who were qualified our screening questions and worth to move the study forward.

\subsection{Sampling Technique}

This study was based on non-probability sampling method using convenient and snowball sampling in order to collect data. Bangkok metropolitan area was selected by the researcher to screen the respondents who had an experience with fitness trackers. The online questionnaires were distributed to various demographical samples randomly by sending questionnaires online from researcher's contact list on each platform mainly Line and Facebook. The Likert scale questionnaires are composed of 10 parts to measure all 10 variables. The volunteers were also advised to forward the submission form link to friends, colleagues, co-workers and relatives as part of the snowball sampling method.

\subsection{Pilot Test}

The reliability test was conducted with 30 respondents. The Cronbach's Alpha Coefficient was implied to test the reliability level of each group of items that are 
concluded in the questionnaire whether it has internal consistency and good reliability or not. According to Figure 4, the Cronbach's Alpha Coefficient for each variable fell in a range of between 0.715 to 0.963 which is greater than 0.7 indicated that the questionnaire achieved the standard requirement indicating high internal consistency met for all research constructs defined according to Tavakol and Dennick (2011). Therefore, this implied that the questionnaires were developed for this study achieved the standard requirement for reliability test and acceptable to carry on the research forward.

Table 1. Reliability Test (Consistency of the scale test $N=30$ )

\begin{tabular}{|l|l|l|l|}
\hline Variables name & $\begin{array}{l}\text { Source of Questionnaire } \\
\text { (Measurement } \\
\text { Indicators) }\end{array}$ & $\begin{array}{l}\text { No. of } \\
\text { items }\end{array}$ & $\begin{array}{l}\text { Cronbach's } \\
\text { Alpha }\end{array}$ \\
\hline Attitude (A) & $\begin{array}{l}\text { Venkatesh, Morris, Davis } \\
\text { and Davis, 2003 }\end{array}$ & 4 & 0.934 \\
\hline Perceived Ease of Use (PE) & Davis, 1989 & 3 & 0.963 \\
\hline Perceived Usefulness (PU) & Davis, 1989 & 5 & 0.809 \\
\hline Affective Quality (AQ) & Kim and Shin, 2015 & 3 & 0.898 \\
\hline Relative Advantage (RA) & $\begin{array}{l}\text { Karahanna, Straub and } \\
\text { Chervan, 1999 }\end{array}$ & 3 & 0.727 \\
\hline Mobility (M) & $\begin{array}{l}\text { Huang, Lin and Chuang, } \\
\text { 2007 }\end{array}$ & 3 & 0.715 \\
\hline Availability (AV) & Shin, 2012 & 4 & 0.932 \\
\hline Subcultural Appeal (SA) & $\begin{array}{l}\text { Sundar, Tamul and Wu, } \\
\text { 2014 }\end{array}$ & 5 & 0.719 \\
\hline Cost (C) & Shin, 2009 & 3 & 0.734 \\
\hline Intention to Use (IU) & Venkatesh et al., 2003 & 3 & 0.769 \\
\hline
\end{tabular}

Source: Author.

\section{Results and Discussion}

\subsection{Demographics}

A total of 671 responses were completed during the survey, but 38 of the responses were excluded because they could not meet the requirements such as with the screening questions either not living in Bangkok Metropolitan area or not owning a fitness tracker. More than half of the respondents were male $(55.8 \%)$ while female accounted for $44.2 \%$ of the total respondents. Most of them aged between 30-39 years $(54.7 \%)$ and $40-49$ years $(28.3 \%)$ old with only $0.5 \%$ of the respondents were 60 years old and above whilst the majority of them were having Thai nationality (99.5\%). Surprisingly, almost all of the respondents $(95.3 \%)$ did not complete their university degree or yet to complete. The two highest group were those who marked their educational level 'below high school' followed by 'high school or equivalent' at the rate of $53.6 \%$ and $41.7 \%$ of total respondents respectively. Subsequently, the 
three highest occupation of the respondents were corporate employees, government officers and business owners at the rate of $55.8 \%, 16.1 \%$ and $13.6 \%$ respectively in which students accounted only $0.9 \%$ of the total respondents. For monthly income level, the first three groups of respondents were fragmented proportionately; $25.3 \%$ with an income of between THB 15,000 - 30,000, 24.8\% with an income of above THB 75,000, 20.4\% with an income of in between THB 30,001 - 45,000. Lastly, more than half of the respondents have been using fitness tracker for more than 2 years at the rate of $64.5 \%$ followed by $13-24$ months at the rate of $22.3 \%$ and the rest (13.2\% of the respondents) are still using fitness trackers less than or equal to 12 months.

Table 2. Demographic Factors

\begin{tabular}{|c|c|c|c|}
\hline \multicolumn{2}{|c|}{ Demographic and Behavior Data $(\mathrm{N}=633)$} & Frequency & Percentage \\
\hline \multirow[t]{2}{*}{ Gender } & Male & 353 & $55.8 \%$ \\
\hline & Female & 280 & $44.2 \%$ \\
\hline \multirow[t]{5}{*}{ Age } & 18-29 years old & 67 & $10.6 \%$ \\
\hline & 30-39 years old & 346 & $54.7 \%$ \\
\hline & 40-49 years old & 179 & $28.3 \%$ \\
\hline & $50-59$ years old & 38 & $6.0 \%$ \\
\hline & 60 and above & 3 & $0.5 \%$ \\
\hline \multirow[t]{2}{*}{ Nationality } & Thai & 630 & $99.5 \%$ \\
\hline & Non-Thai & 3 & $0.5 \%$ \\
\hline \multirow[t]{6}{*}{ Education } & Less than high school & 339 & $53.6 \%$ \\
\hline & High school or equivalent & 264 & $41.7 \%$ \\
\hline & Bachelor & 15 & $2.4 \%$ \\
\hline & Master & 7 & $1.1 \%$ \\
\hline & Doctoral & 5 & $0.8 \%$ \\
\hline & Other & 3 & $0.5 \%$ \\
\hline \multirow[t]{6}{*}{ Occupation } & Corporate employee & 353 & $55.8 \%$ \\
\hline & Business owner & 86 & $13.6 \%$ \\
\hline & Government officer & 102 & $16.1 \%$ \\
\hline & Freelance & 49 & $7.7 \%$ \\
\hline & Students & 6 & $0.9 \%$ \\
\hline & Other & 37 & $5.8 \%$ \\
\hline \multirow[t]{6}{*}{ Income level } & Less tha Bt15,000 & 38 & $6.0 \%$ \\
\hline & Bt15,000-Bt30,000 & 160 & $25.3 \%$ \\
\hline & Bt30,001-Bt45,000 & 129 & $20.4 \%$ \\
\hline & Bt45,001-Bt60,000 & 96 & $15.2 \%$ \\
\hline & Bt60,001-Bt75,000 & 53 & $8.4 \%$ \\
\hline & Bt75,001 and above & 157 & $24.8 \%$ \\
\hline \multirow[t]{5}{*}{ Period of usage } & Less than 3 months & 21 & $3.3 \%$ \\
\hline & 3-6 months & 30 & $4.7 \%$ \\
\hline & 7-12 months & 33 & $5.2 \%$ \\
\hline & 13-24 months & 141 & $22.3 \%$ \\
\hline & More than 24 months & 408 & $64.5 \%$ \\
\hline
\end{tabular}




\subsection{Confirmatory Factor Analysis (CFA)}

CFA has provided the validation tests of how the data fits with the conceptual model in this research. To elaborate, CFA helps to examine the result of factor loading, composite reliability (CR) and average variance extracted (AVE). The factor loading should be higher than 0.3 (Kline, 1994). In addition, the composite reliability (CR) should be above 0.7 and the average variance extracted (AVE) that used for convergent validity should be above 0.5 (Hair et al., 2010). According to Figure 6, the result of composite reliability (CR) and the average variance extracted (AVE) are showed, which are greater than 0.7 and 0.5 respectively.

The square root of the average variance extracted (AVE) is a method to help access the discriminant validity which is usually used to test between variables. In general, each individual variable should be greater than the covariant relation between the variables in the model. It is confirmed that the correlation coefficients between two variables are smaller than the square root of AVE in Table 4. Note that the confirmatory factor analysis constructed an explainable fit of the data to the tenthfactor measurement model on various criteria by utilizing correlation analysis to determine dimensionality, convergence and discriminant validity. All of the outcomes were greater than the suggested criteria (Table 5). Thus, there was a good acceptable model fit between the theoretical model and the data.

Table 3. Confirmatory factor analysis results, Composite Reliability (CR) and Average Variance Extracted (AVE)

\begin{tabular}{|c|c|c|c|c|c|}
\hline Variable & Factor Loading & S.E. & T-value & $\mathbf{C R}$ & AVE \\
\hline $\begin{array}{l}\text { Cost }(\mathrm{C}) \\
\mathrm{C} 1 \\
\mathrm{C} 2 \\
\mathrm{C} 3\end{array}$ & $\begin{array}{l}0.614 \\
0.885 \\
0.604 \\
\end{array}$ & $\begin{array}{l}0.054 \\
0.173 \\
0.076 \\
\end{array}$ & $\begin{array}{l}8.331 * * * \\
1.575 * * * \\
16.944 * * *\end{array}$ & 0.750 & 0.508 \\
\hline $\begin{array}{l}\text { Subcultural Appeal (SA) } \\
\text { SA1 } \\
\text { SA2 } \\
\text { SA3 } \\
\text { SA4 } \\
\text { SA5 }\end{array}$ & $\begin{array}{l}0.687 \\
0.590 \\
0.652 \\
0.878 \\
0.737\end{array}$ & $\begin{array}{l}0.190 \\
0.584 \\
0.873 \\
0.510\end{array}$ & $\begin{array}{l}3.634 * * * \\
5.044 * * * \\
4.62 * * * \\
4.662 * * *\end{array}$ & 0.837 & 0.512 \\
\hline $\begin{array}{l}\text { Availability (AV) } \\
\text { AV1 } \\
\text { AV2 } \\
\text { AV3 } \\
\text { AV4 }\end{array}$ & $\begin{array}{l}0.885 \\
0.938 \\
0.719 \\
0.878 \\
\end{array}$ & $\begin{array}{l}0.034 \\
0.036 \\
0.034 \\
\end{array}$ & $\begin{array}{l}34.538^{* * *} \\
21.646^{* * *} \\
31.156^{* * *}\end{array}$ & 0.918 & 0.738 \\
\hline $\begin{array}{l}\text { M (Mobility) } \\
\text { M1 } \\
\text { M2 } \\
\text { M3 }\end{array}$ & $\begin{array}{l}0.755 \\
0.913 \\
0.471 \\
\end{array}$ & $\begin{array}{l}0.109 \\
0.101 \\
\end{array}$ & $\begin{array}{l}12.108 * * * \\
11.113 * * *\end{array}$ & 0.769 & 0.542 \\
\hline $\begin{array}{l}\text { Relative Advantage (RA) } \\
\text { RA1 } \\
\text { RA2 } \\
\text { RA3 }\end{array}$ & $\begin{array}{l}0.544 \\
0.767 \\
0.843 \\
\end{array}$ & $\begin{array}{l}0.074 \\
0.081 \\
\end{array}$ & $\begin{array}{l}12.068 * * * \\
11.539 * * *\end{array}$ & 0.768 & 0.532 \\
\hline Affective Quality (AQ) & & & & 0.805 & 0.587 \\
\hline
\end{tabular}




\begin{tabular}{|l|l|l|l|l|l|} 
AQ1 & 0.676 & & & & \\
AQ2 & 0.642 & 0.063 & $14.704^{* * *}$ & & \\
AQ3 & 0.945 & 0.089 & $14.13^{* * *}$ & & \\
\hline Perceived Ease of Use (PE) & & & & 0.892 & 0.735 \\
PE1 & 0.827 & 0.046 & $26.555^{* * *}$ & & \\
PE2 & 0.979 & 0.048 & $22.138^{* * *}$ & & \\
PE3 & 0.751 & & & 0.829 & 0.511 \\
\hline Perceived Usefulness (PU) & & & & & \\
PU1 & 0.662 & 0.900 & $12.779^{* * *}$ & & \\
PU2 & 0.531 & 0.115 & $12.632^{* * *}$ & & \\
PU3 & 0.983 & 0.096 & $18.029^{* * *}$ & & \\
PU4 & 0.811 & 0.088 & $18.426^{* * *}$ & & \\
PU5 & 0.798 & & & 0.831 & 0.621 \\
\hline Intention to use (IU) & 0.813 & 0.052 & $18.138^{* * *}$ & & \\
IU1 & 0.751 & 0.049 & $17.631^{* * *}$ & & \\
IU2 & & & & 0.933 & 0.777 \\
IU3 & 0.919 & 0.049 & $27.005^{* * *}$ & & \\
\hline Attitude (A) & 0.954 & 0.043 & $27.998^{* * *}$ & & \\
A1 & 0.856 & 0.042 & $29.710^{* * *}$ & & \\
A2 & 0.787 & & & & \\
A3 & & & \\
A4 & & & & \\
\hline
\end{tabular}

Note: $C R=$ Composite Reliability, $A V E=$ Average Variance Extracted $* * *=$ Significant at the 0.05 significant levels $(p<0.05)$

Source: Author.

Table 4. Discriminant Validity

\begin{tabular}{|l|l|l|l|l|l|l|l|l|l|l|}
\hline & A & IU & PE & PU & AQ & RA & M & AV & SA & C \\
\hline A & $\mathbf{0 . 8 8 1}$ & & & & & & & & & \\
\hline IU & 0.017 & $\mathbf{0 . 7 8 8}$ & & & & & & & & \\
\hline PE & 0.293 & 0.027 & $\mathbf{0 . 8 5 8}$ & & & & & & & \\
\hline PU & 0.523 & 0.02 & 0.246 & $\mathbf{0 . 7 1 5}$ & & & & & & \\
\hline AQ & 0.474 & 0.035 & 0.279 & 0.600 & $\mathbf{0 . 7 6 6}$ & & & & & \\
\hline RA & 0.557 & 0.029 & 0.269 & 0.573 & 0.634 & $\mathbf{0 . 7 2 9}$ & & & & \\
\hline M & 0.496 & 0.033 & 0.402 & 0.458 & 0.479 & 0.550 & $\mathbf{0 . 7 3 6}$ & & & \\
\hline AV & 0.436 & 0.059 & 0.377 & 0.441 & 0.475 & 0.456 & 0.494 & $\mathbf{0 . 8 5 9}$ & & \\
\hline SA & 0.523 & 0.036 & 0.416 & 0.376 & 0.493 & 0.418 & 0.438 & 0.336 & $\mathbf{0 . 7 1 5}$ & \\
\hline C & -0.049 & -0.066 & -0.061 & 0.026 & 0.009 & -0.033 & 0.022 & -0.025 & -0.082 & $\mathbf{0 . 7 1 3}$ \\
\hline
\end{tabular}

Note: The diagonally listed values are the AVE square roots of the variables

Source: Author.

Table 5. Goodness of Fit

\begin{tabular}{|l|l|l|}
\hline Index & Criteria & Result of this study \\
\hline CMIN/DF & $<3.00$ (Hair, et al., 2010) & 2.598 \\
\hline GFI & $>0.90$ (Hair, et al., 2010) & 0.907 \\
\hline AGFI & $>0.90$ (Tanaka \& Huba, 1984) & 0.903 \\
\hline NFI & $>0.90$ (Arbuckle, 1995) & 0.928 \\
\hline
\end{tabular}




\begin{tabular}{|l|l|l|} 
CFI & $>0.90($ Hu \& Betler, 1999; Marsh, Hau, \& Wen 2004) & 0.954 \\
\hline TLI & $>0.90($ Hu \& Betler, 1999; Marsh, et al., 2004) & 0.937 \\
\hline RMSEA & $<0.08$ (Hu \& Betler, 1999) & 0.050 \\
\hline RMR & $<0.05$ (Hair, et al., 2010) & 0.049 \\
\hline
\end{tabular}

Note: $C M I N / D F=$ The ratio of the chi-square value to degree of freedom, GFI = goodnessof-fit index, AGFI = adjusted goodness-of-fit index, NFI, normalized fit index, CFI = comparative fit index, TLI = Tucker-Lewis index, RMSEA = root mean square error of approximation, and $R M R=$ root mean square residual

Source: Author.

\subsection{Test of Structural Model}

The calculation of Structural Equation Model (SEM) was done using AMOS 18.0. The outcomes from SEM were measured against goodness-of-fit index depicted above in Table 5. The overall modeling achieved significance and represented satisfactory results as per its goodness-of-fit induces as all suggested values were met: $\mathrm{CMIN} / \mathrm{DF}=2.598, \mathrm{GFI}=0.907, \mathrm{AGFI}=0.903, \mathrm{NFI}=0.928, \mathrm{CFI}=0.954, \mathrm{TLI}$ $=0.937, \mathrm{RMSEA}=0.050$ and $\mathrm{RMR}=0.049$. All results were greater or higher than the suggested criteria which pointed out an acceptable fit with model between data and the theoretical model of this research. However, few researchers allow value of 5 to be the maximum in order to consider an adequate fit model (for instance the research by Schumacker and Lomax, 2004).

\subsection{Hypothesis Testing Results}

Table 6 below represents the results of the hypothesized test. In summary, there were $\mathrm{H}_{1}, \mathrm{H}_{2}, \mathrm{H}_{3}, \mathrm{H}_{5}, \mathrm{H}_{6}, \mathrm{H}_{9}$ and $\mathrm{H}_{10}$ that resulted in supported whilst the hypotheses $\mathrm{H}_{4}$, $\mathrm{H}_{7}, \mathrm{H}_{8}$, and $\mathrm{H}_{11}$ whose results were not supported.

Table 6. Hypotheses Result of the Structural Model

\begin{tabular}{|l|l|l|l|}
\hline Hypothesis & $\begin{array}{l}\text { Standardized } \\
\text { path } \\
\text { coefficient }(\boldsymbol{\beta})\end{array}$ & T-value & Test result \\
\hline $\mathrm{H}_{1}:$ Affective Quality => Perceived Usefulness & 0.156 & $2.878 * * *$ & Supported \\
\hline $\begin{array}{l}\mathrm{H}_{2}: \text { Relative Advantage => Perceived } \\
\text { Usefulness }\end{array}$ & 0.626 & $9.897 * * *$ & Supported \\
\hline $\mathrm{H}_{3}:$ Mobility => Perceived Ease of Use & 0.511 & $9.600 * * *$ & Supported \\
\hline $\mathrm{H}_{4}:$ Availability => Perceived Ease of Use & 0.061 & 1.215 & $\begin{array}{l}\text { Not } \\
\text { Supported }\end{array}$ \\
\hline $\mathrm{H}_{5}:$ Perceived Usefulness => Attitude & 0.354 & $8.064 * * *$ & Supported \\
\hline $\mathrm{H}_{6}:$ Perceived Usefulness => Intention to Use & 0.454 & $8.855^{* * *}$ & Supported \\
\hline $\begin{array}{l}\mathrm{H}_{7}: \text { Perceived Ease of Use => Perceived } \\
\text { Usefulness }\end{array}$ & 0.026 & 0.967 & $\begin{array}{l}\text { Not } \\
\text { Supported }\end{array}$ \\
\hline $\mathrm{H}_{8}:$ Perceived Ease of Use => Attitude & 0.034 & 1.331 & $\begin{array}{l}\text { Not } \\
\text { Supported }\end{array}$ \\
\hline $\mathrm{H}_{9}:$ Attitude has => Intention to Use & 0.568 & $6.874 * * *$ & Supported \\
\hline
\end{tabular}




\begin{tabular}{|l|l|l|l|}
\hline $\mathrm{H}_{10}:$ Subcultural Appeal => Attitude & 0.496 & $4.396 * * *$ & Supported \\
\hline $\mathrm{H}_{11}:$ Cost $=>$ Intention to Use & -0.016 & -0.34 & $\begin{array}{l}\text { Not } \\
\text { Supported }\end{array}$ \\
\hline
\end{tabular}

Note: $* * * p<0.05$

Source: Author.

\subsection{Hypotheses Summary}

$\mathrm{H}_{1}$ : The standardized track of coefficient in between affective quality and perceived usefulness was $0.156\left(\mathrm{t}\right.$-value $\left.=2.878^{* * *}\right)$. Affective quality has significantly direct effect on perceived usefulness. Thus, $\mathrm{H}_{1}$ was supported.

$\mathrm{H}_{2}$ : The standardized track of coefficient in between relative advantage and perceived usefulness was 0.626 (t-value $=9.897^{* *}$ ). Relative advantage has significantly direct effect on perceived usefulness. Thus, $\mathrm{H}_{2}$ was supported.

$\mathrm{H}_{3}$ : The standardized track of coefficient in between mobility and perceived ease of use was 0.511 (t-value $=9.600 * * *$ ). Mobility has significantly direct effect on perceived ease of use. Thus, $\mathrm{H}_{3}$ was supported.

$\mathrm{H}_{4}$ : The standardized track of coefficient in between availability and perceived ease of use was 0.0616 (t-value $=1.215$ ). Availability has no significantly direct effect on perceived ease of use. Thus, $\mathrm{H}_{4}$ was not supported.

$\mathrm{H}_{5}$ : The standardized track of coefficient in between perceived usefulness and attitude was $0.354\left(\mathrm{t}\right.$-value $\left.=8.064^{* * *}\right)$. Perceived usefulness has significantly direct effect on attitude. Thus, $\mathrm{H}_{5}$ was supported.

$\mathrm{H}_{6}$ : The standardized track of coefficient in between perceived usefulness and intention to use was 0.454 (t-value $=8.855^{* * *}$ ). Perceived usefulness has significantly direct effect on intention to use. Thus, $\mathrm{H}_{6}$ was supported.

$\mathrm{H}_{7}$ : The standardized track of coefficient in between perceived ease of use and perceived usefulness was 0.026 (t-value $=0.967)$. Perceived ease of use has no significantly direct effect on perceived usefulness. Thus, $\mathrm{H}_{7}$ was not supported.

$\mathrm{H}_{8}$ : The standardized track of coefficient in between perceived ease of use and attitude was $0.034(\mathrm{t}$-value $=1.331)$. Perceived ease of use has no significantly direct effect on attitude. Thus, $\mathrm{H}_{8}$ was not supported.

$\mathrm{H}_{9}$ : The standardized track of coefficient in between attitude and intention to use was 0.568 (t-value $=6.874 * * *)$. Attitude has significantly direct effect on intention to use. Thus, $\mathrm{H}_{9}$ was supported. 
$\mathrm{H}_{10}$ : The standardized track of coefficient in between subcultural appeal and attitude was $0.496\left(\mathrm{t}\right.$-value $\left.=4.396^{* * *}\right)$. Subcultural appeal has significantly direct effect on attitude. Therefore, $\mathrm{H}_{10}$ was supported.

$\mathrm{H}_{11}$ : The standardized track of coefficient in between cost and intention to use was 0.016 (t-value $=-0.34$ ). Cost represented to have no direct effect on intention to use. Therefore, $\mathrm{H}_{11}$ was not supported.

\subsection{Direct, Indirect and Total Effects of Relationships}

The outcomes of all relationships based on the direct, indirect and total effects also resulted from AMOS software. Basically, when there is a direct effect between variables, it can be implied that an independent variable directly impact on the dependent variable without any mediating variables. On the contrary, indirect effect meant that an independent variable somehow indirectly effect the dependent variable via mediating variables. The details of the effects are shown below in Table 7.

Table 7. Direct, Indirect and Total Effects of Relationships

\begin{tabular}{|c|c|c|c|c|c|c|c|c|c|c|}
\hline \multirow[b]{2}{*}{ Dependent Variables } & \multicolumn{10}{|c|}{ Independent variables } \\
\hline & Effrect & $\begin{array}{c}\text { Affect } \\
\text { Quality }\end{array}$ & $\begin{array}{c}\text { Relative } \\
\text { Advantage }\end{array}$ & Mobility & Availability & $\begin{array}{l}\text { Perceived } \\
\text { Usefulness }\end{array}$ & \begin{tabular}{|c|} 
Perceived \\
Ease of Use \\
\end{tabular} & Attitude & Subcultural & Cost \\
\hline \multirow[t]{4}{*}{ Perceived Usefulness } & $\mathrm{DE}$ & $0.156^{* * * *}$ & $0.626^{* * *}$ & - & - & - & 0.026 & - & - & - \\
\hline & $\mathrm{IE}$ & - & - & - & - & - & & - & - & - \\
\hline & $\mathrm{TE}$ & $0.156^{* * * *}$ & $0.626^{* * *}$ & - & - & - & 0.026 & - & - & - \\
\hline & $\mathrm{R} 2$ & \multicolumn{9}{|c|}{0.579} \\
\hline \multirow[t]{4}{*}{ Perceived Ease of Use } & $\mathrm{DE}$ & - & - & $0.511 * * *$ & 0.061 & - & - & - & - & - \\
\hline & $\mathrm{IE}$ & - & - & - & - & - & - & - & - & - \\
\hline & $\mathrm{TE}$ & - & - & $0.511 * * *$ & 0.061 & - & - & - & - & - \\
\hline & $\mathrm{R} 2$ & \multicolumn{9}{|c|}{0.296} \\
\hline \multirow[t]{4}{*}{ Attitude } & $\mathrm{DE}$ & - & - & - & - & $0.354 * * *$ & 0.034 & - & $0.496 * * *$ & - \\
\hline & IE & - & - & - & - & - & - & - & - & - \\
\hline & $\mathrm{TE}$ & - & - & - & - & $0.354 * * *$ & 0.034 & - & 0.496 *** & - \\
\hline & $\mathrm{R} 2$ & \multicolumn{9}{|c|}{0.585} \\
\hline \multirow[t]{4}{*}{ Intention to Use } & $\mathrm{DE}$ & - & - & - & - & 0.454 & - & 0.568 & - & -0.016 \\
\hline & $\mathrm{IE}$ & - & - & - & - & 0.009 & 0.001 & - & - & \\
\hline & $\mathrm{TE}$ & - & - & - & - & 0.463 & 0.001 & 0.568 & - & -0.016 \\
\hline & $\mathrm{R} 2$ & \multicolumn{9}{|c|}{0.001} \\
\hline
\end{tabular}

\section{Source: Author.}

Based on the direct effect, the strongest influence on perceived usefulness is from the relative advantage (0.626), followed by affective quality (0.156). Perceived usefulness is influenced sole by the mobility (0.511) and the highest influence on attitude is from subcultural (0.496), then perceived usefulness (0.354). Lastly, intention to use fitness tracker is mostly influenced by attitude (0.568), followed by perceived usefulness (0.454). Unfortunately, there is no significant influence between cost and the intention to use fitness tracker according to the result of the structural model. Thence, affective quality, relative advantage, mobility, perceived 
usefulness, subcultural appeal, and attitude are all significant to influence direct and indirect impact to intention to use fitness tracker.

Figure 4. The Structural Model Results

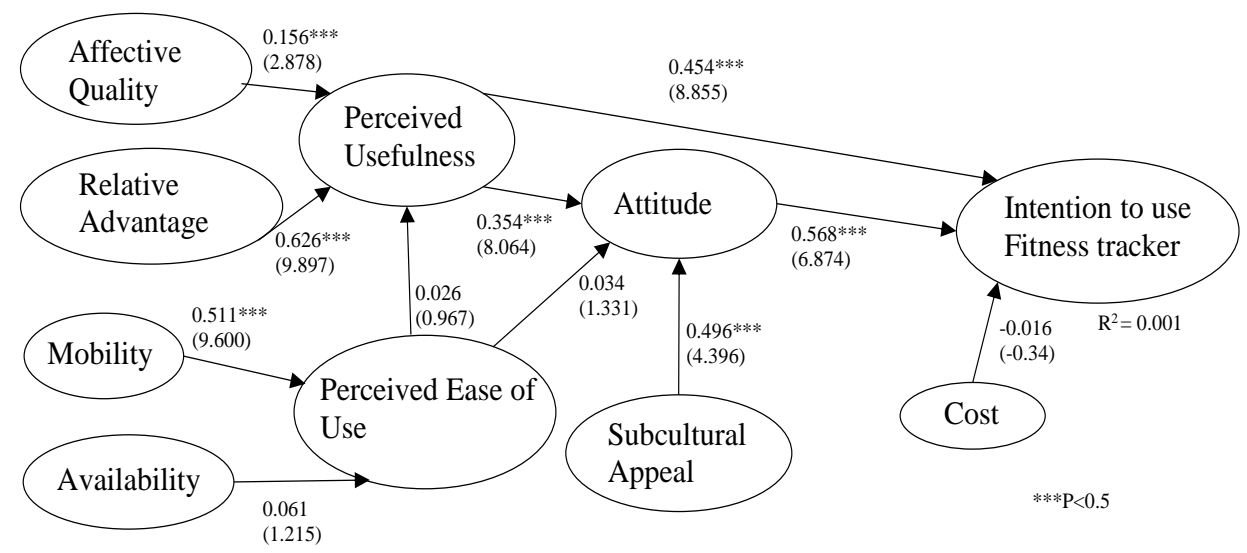

Source: Author.

In structural pathway of affective quality to perceived usefulness $\left(\mathrm{H}_{1}\right)$, it is significantly influenced with coefficient of 0.156 . The result was showed that consumer's affective quality is determined by "attractive and pleasing" (0.792), followed by "feel excited" (0.770) and "miss using" (0.770). This result has aligned with past research of Seva et al. (2007), and Tom Dieck and Jung, (2018).

For the pathway of relative advantage and perceived usefulness $\left(\mathrm{H}_{2}\right)$, there is a significant influence with coefficient of 0.626 . Consumers have considered relative advantage as "greater advantage and offers more functions" (0.792) and "advantage outweigh its disadvantage" (0.781), instead of "improving quality of work" (0.591). Therefore, consumer would perceive a product useful if the product is mainly attractive, pleasing, and have greater advantage when comparing with other substitutes or its own disadvantage. This finding is aligned with the previous research of Bennett and Bennett (2003), Rogers (1995), and Jeong, Kim, Park and Choi (2017).

On the structural pathway of mobility to perceived ease of use $\left(\mathrm{H}_{3}\right)$, the hypothesis is supported with coefficient of 0.511 . Mobility for the consumers are characterized as "good mobility" (0.830) and "able to use anywhere" (0.822), which outweigh the "using when transit from one place to another". This finding are in line with the previous research of Kynaslahti (2003) and Buenaflor and Kim (2013). The concept of "anywhere-anytime" is one of the important factors to persuade the product's ease of use to consumer. 
For $\mathrm{H}_{4}$ of structural pathway from availability to perceived ease of use, there is no significant influence and therefore the hypothesis is not supported. Consumers perceived that the availability in the aspect like "real-time connection" $(0.997)$ does not influence the product's ease of use. This finding has contradicted with the past research of Adapa, Nah, Hall, Siau, and Smith (2018).

Perceived usefulness has hypothesized to have significant direct impact on attitude $\left(\mathrm{H}_{5}\right)$ and intention to use fitness tracker $\left(\mathrm{H}_{6}\right)$. The hypotheses are supported with coefficient of 0.354 and 0.454 , respectively. The consumer's main aspects of perceived usefulness are "helps complete tasks productively" (0.817), "improves ability to complete tasks" (0.802), and "easier to complete tasks" $(0.750)$. Which means that when a product can assist consumer in completing task faster and easier through its features, advantage and attractiveness, the consumer would perceive the product as useful. This would lead to a significant influence on attitude towards the product and intention to use the fitness trackers. These outcomes have also reflected the past research of Chuah et al. (2016), Koo (2018), Pfeffer (1982), Schein (1980), and Vroom (1964).

Perceived ease of use has hypothesized to have significant direct impact on perceived usefulness $\left(\mathrm{H}_{7}\right)$ and attitude $\left(\mathrm{H}_{8}\right)$. However, both hypotheses are not support according to this research study. Perceived ease of use is indicated by consumers as "easy to use" $(0.952)$ and "easy to operate" $(0.838)$. The findings contradict with previous research of Koo (2018), Lunney, Cunningham and Eastin (2016), and Kim and Chiu (2019).

$\mathrm{H}_{9}$ hypothesized that attitude has a significantly direct impact on intention to use fitness tracker. The hypothesis is supported with coefficient of 0.568 . The important factors that formed the attitudes for consumer according to SEM results are "favorable attitude towards using" (0.947), "beneficial" (0.919), "good idea" (0.904), then "like the idea of using" (0.869). So, to form a positive consumer's attitudes towards the product, the product needs to be attractive, beneficial and useful in completing task. This would subsequently result to higher direct impact to intention to use fitness tracker. This finding is aligned with the previous studies of Krey, Chuah, Ramayah, and Rauschnabel (2019), Wu, Wu, and Chang (2016), Rauschnabel and Ro (2016), Kabayadi and Gupta (2011), Lorenzo-Romero et al. (2011), Oyedele and Minor (2011), and Zorn et al. (2010).

For $\mathrm{H}_{10}$, the hypothesis of subcultural appeal has a significantly direct impact on attitude is supported with coefficient of 0.496 . The consumers have characterized subcultural appeal as "using smart watch would considered to be leader" $(0.870)$ and "using smart watch is unique" (0.759). Since smart watch is a product from the recent technological advancements, consumers using smart watch would consider themselves as leader in using technological products and subjected to a niche group of people. This finding follows the previous research of Kim and Shin (2015). 
The last structural pathway of cost to intention to use fitness tracker $\left(\mathrm{H}_{11}\right)$ has no significant direct impact according to SEM result. Cost in the definition of consumer is that "purchasing was a burden" (0.897). However, there is no influence on intention to use as smart watch is an innovative product which can be costly due to its feature. Whereas, consumer decision to use smart watch has instead depending on the favorable attitude towards the product and its usefulness. This finding is aligned with the previous research of Talukder, Chiong, Bao and Hayat Malik (2019).

\section{Conclusion}

This study aims to study numerous factors affecting intention to use fitness tracker in Bangkok metropolitan area, Thailand. According to previous studies, a conceptual framework was developed as per the extended version of TAM theory whereby consists of affective quality, relative advantage, mobility, availability, perceived usefulness, perceived ease of use, attitude, subcultural appeal, cost and intention to use. The researcher used online survey as a method to distribute the questionnaires to target respondents living in Bangkok metropolitan area and have experienced in using fitness tracker. The results were analyzed using CFA to verify the validity and reliability of the model. Furthermore, SEM was also used to examine the influence among the variables.

Consequently, despite no clear direct effect between availability and perceived ease of use, perceived ease of use and attitude, perceived ease of use and perceived usefulness and lastly cost and the intention to use fitness tracker, the model demonstrated that the greater consumer's perceived usefulness and attitude, the more likely that consumer would intent to use fitness tracker. To enhance consumers' perceived usefulness, the product should be attractive, excited (affective quality) and offers greater advantage and features over the other (relative advantage). Perceived usefulness is also one of the factors leading to a positive consumers' attitude.

However, subcultural appeal also plays an important role towards attitude due to its greater degree of influence compared to perceived usefulness. Added to such, the "anywhere-anytime" characteristic also proved to have a significant effect in terms of perceived ease of use. Finally, the non-significant relationship between cost and the intention to use are noteworthy findings. For example, the non-significant relationship between cost and intention to use can imply that, regardless of the high cost of fitness trackers, consumers still purchase it anyways because of its high value on the back of how effectively it can help them improve their performance. Notably, more than $86 \%$ of the respondents have been already using fitness tracker for more than 12 months.

\section{Recommendations}

The proposed revised model of TAM in this case somehow may not completely justify the factors directly affecting the intention to use fitness tracker in Bangkok 
metropolitan area, whereas only 7 hypotheses were valid in terms of statistically significant results. After all, only 2 out of 3 factors were valid to help explain the phenomenal why consumer intend to use fitness tracker which were perceived usefulness and attitude. To elaborate further, these are the fundamental side of the logical thinking when people are going to make a decision to adopt something new. It has to be better than the precedent that provides incremental benefits.

Therefore, the key messages for the marketers of fitness tracker are to make a clear statement on the differences of product performance and features comparing to the prior or existing one in the market (relative advantage). Also, products' performance and features should be presented in an attractive (affective quality) and privilege way that would made consumer feels superior (subcultural appeal) and useful in using the producs. These key messages and their theme could be portraying on the product's advertisement. In addition, researcher suggested that other emotional factors may weight more than the perceived usefulness, attitude and cost. For example, cost should have an indirect relationship with an intention to use fitness tracker, as cost to acquire products increase, the intention will eventually decrease which may imply that fitness tracker could be a kind of Veblen good as it can represent a symbol of healthy and active lifestyle for the users as they seek status on conspicuous consumption (Veblen, 1899).

\section{Limitations and Further Study}

The findings had certain limitations that should be discussed in further study. Firstly, the target respondents of the study was only those living in Bangkok metropolitan area, further study should account more provincial population in the study for a more diverse lifestyle of people and different demographic landscape. Secondly, it is worth finding further on the less important relationship in between cost against the intention to use. Thirdly, it is possible to add few emotional variables such as the appearance and social value or influence to the model because TAM theory hardly pointed out the role of other users while influencing an individual's behavior. This is something to highlight as many psychological researches certainly proved that other people surrounding the individual can influence the individual's behavior in broader terms.

\section{References:}

Adapa, A., Nah, F.F.H., Hall, R.H., Siau, K., Smith, S.N. 2018. Factors influencing the adoption of smart wearable devices. International Journal of Human-Computer Interaction, 34(5), 399-409.

Alfred, S.B. 1992. Price Inelasticity: Not All That Meets The Eye. Journal of Consumer Marketing, 2(3), 61-66.

Arbuckle, J. 1995. AMOS: Analysis of moment structures user's guide. Chicago, Small Waters. 
Bennett, J., Bennett, L. 2003. A review of factors that influence the diffusion of innovation when structuring a faculty training program. The Internet and Higher Education, 6, 53-63.

Britt, S.H. 1996. Consumer Behavior and the Behavioral Sciences. New York, NY, Wiley.

Buenaflor, C., Kim, H.C. 2013. Six human factors to acceptability of wearable computers. International Journal of Multimedia and Ubiquitous Engineers, 8(3), 103-114.

Chuah, S.H.W., Rauschnabel, P.A., Krey, N., Nguyen, B., Ramayah, T., Lade, S. 2016. Wearable technologies: the role of usefulness and visibility in smartwatch adoption. Computers in Human Behavior, 65, 276-284.

Davis, F.D., Bagozzi, R., Warshaw, P.R. 1989. User Acceptance of Computer Technology: A Comparison of Two Theoretical Models. Management Science, 35(8), 982-1003.

Davis, F.D. 1986. A technology acceptance model for empirically testing new end-user information systems: theory and results. Doctoral dissertation, MIT Slone School of Management, Cambridge, MA.

Davis, F.D. 1989. Perceived usefulness, perceived ease of use, and user accpetance of information technology. MIS Quarterly, 13(3), 319-342.

Elder, G. 1985. Life Course Dynamics. Ithaca, Cornell University Press.

Fishbein, M.A., Ajzen, I. 1975. Belief, Attitude, Intention and Behavior: An Introduction to Theory and Research. Reading, MA, Addison-Wesley.

Gartner. 2018. Gartner say worldwide wearable device sales to grow 226 percent in 2019. Retrived from .

Hair, J.F., Black, W.C., Babin, B.J., Anderson, R.R. 2010. Multivariate Data Analysis (6 ${ }^{\text {th }}$ ed.). Upper Saddle River, NJ. Prentice Hall, 137-142.

$\mathrm{Hu}$ and Bentler. 1999. Cutoff criteria for fit indexes in covariance structure analysis: Conventional criteria versus new alternatives. Structural Equation Modeling, 6(1), 155.

Huang, J.H., Lin, Y.R., Chuang, S.T. 2007. Elucidating user behavior of mobile learning. Electronic Library, 25(5), 585-598.

Jeong, S.C., Kim, S.H., Park, J.Y., Choi, B. 2017. Domain-specific innovativeness and new product adoption: a case of wearable devices. Telematics and Informatics, 34(5), 399-412.

Kabayadi, S., Gupta, R. 2011. Managing motives and design to influence web site revisits. Journal of Research in Interactive Marketing, 5(2/3), 153-169.

Karahanna, E., Straub, D.W., Chervan, N.L. 1999. Information technology adoption across time: a cross-sectional comparison of pre-adoption and post-adoption beliefs. MIS Quarterly, 23(2), 183-213.

Kim, K.J., Shin, D.H. 2015. An acceptance model for smart watches: implications for the adoption of future wearable technology. Internet Research, 25(4), 527-541.

Kim, T., Chiu, W. 2019. Consumer acceptance of sports wearable technology: the role of technology readiness. International Journal of Sports Marketing and Sponsorship, 20(1), 109-126.

Kline, P. 1994. An Easy Guide to Factor Analysis. New York, USA, Routledge.

Koo, S.H. 2018. Design factors and preferences in wearable soft robots for movement disabilities. International Journal of Clothing Science and Technology, 30(4), 477495.

Kotler, P. 2000. Marketing Management: Analysis, Planning, Implementation and Control (10 ${ }^{\text {th }}$ ed.). Englewood Cliffs, NJ, Prentice-Hall. 
Krey, N., Chuah, S.H.W., Ramayah, T., Rauschnabel, P.A. 2019. How functional and emotional ads drive smartwatch adoption: The moderating role of consumer innovativeness and extraversion. Internet Research, 29(3), 578-602.

Kurosu, M., Kashimura. K. 1995. Apparent usability vs. inherent usability experimental analysis on the determinants of the apparent usability. CHI '95 Conference Companion on Human Factors in Computing Systems, 2, 292-293.

Kynaslahti, H. 2003. In search of elements of mobility in the context of education. In Kynaslahti, H. and Seppala, P. (Eds). Mobile learnings, 41-48. Helsinki, IT Press.

Lorenzo-Romerro, C., Constantinides, E., Alarcon-del-Amo, M. 2011. Consumer adoption of social networking sites: implications for theory and practice. Journal of Research in Interactive Marketing, 5(2/3), 170-188.

Luarn, P., Lin, H.H. 2005. Toward an understanding of the behavioral intention to use mobile banking. Computers in Human Behavior, 21(6), 873-891.

Lunney, A., Cunningham, N.R., Eastin, M.S. 2016.Wearable fitness technology: a structural investigation into acceptance and perceived fitness outcomes. Computers in Human Behavior, 65, 114-120.

Marsh, H.W., Hau, K.T., Wen, Z. 2004. In search of golden rules: Comment on hypothesistesting approaches to setting cutoff values for fit indexes and dangers in overgeneralizing Hu and Bentler's (1999) findings. Structural equation modeling, 11(3), 320-341.

Oyedele, A., Minor, M.S. 2011. Customer typology: 3D virtual world. Journal of Research in Interactive Marketing, 5(1), 29-49.

Pfeffer, J. 1982. Organizations and Organization Theory. Boston, MA, Pitman.

Radner, R., Rothchild, M. 1975. On the Allocation of Effort. Journal of Economic Theory, 10, 358-376.

Rauschnabel, P.A., Ro, Y.K. 2016. Augmented reality smart glasses: an investigation of technology acceptance drivers. International Journal of Technology Marketing, 11(2), 123-148.

Rogers, E.M. 1995. Diffusion of Innovation (4 ${ }^{\text {th }}$ ed.). New York, NY, Free Press.

Seva, R.R., Duh, H.B., Helander, M.G. 2007. The marketing implications of affective product design. Appl Ergon, 38, 723-731.

Schein, E.H. 1980. Organizational Psychology ( $3^{\text {rd }}$ ed.). Englewood Cliffs, NJ, Prentice-Hall.

Shin, D.H. 2009. Determinants of customer acceptance of multi-service network: an implication for IP-based technologies. Information and Management, 46(1), 16-22.

Shin, D.H. 2012. What makes consumers use VoIP over mobile phones? Free riding or consumerization of new service. Telecommunications Policy, 36(4), 311-323.

Schumacker, R.E., Lomax, R.G. 2004. A beginner's guide to structural equation modeling ( $2^{\text {nd }}$ ed.). Mahwah, NJ, US, Lawrence Erlbaum Associates Publishers.

Sundar, S.S., Tamul, D., Wu, M. 2014. Capturing 'cool': measures for assessing coolness of technological products. International Journal of Human-Computer Studies, 72(2), 169-180.

Talukder, M.S., Chiong, R., Bao, Y., Hayat Malik, B. 2019. Acceptance and use predictors of fitness wearable technology and intention to recommend: An empirical study. Industrial Management \& Data Systems, 119(1), 170-188.

Tanaka, J.S., Huba, G.J. 1984. Confirmatory hierarchical factor analyses of psychological distress measures. Journal of Personality and Social Psychology, 46(3), 621-635. https://doi.org/10.1037/0022-3514.46.3.621.

Tavakol, M., Dennick, R. 2011. Making sense of Cronbach's alpha. International Journal of Medical Education, 53-55. 
Thai Health Promotion Foundation. 2018. 'Running' and The New 'Standards' that Should be Reach. Retrieved from https://www.thaihealth.or.th/.

Tom Dieck, M.C. and Jung, T. 2018. A theoretical model of mobile augmented reality acceptance in urban heritage tourism. Current Issues in Tourism, 21(2), 154-174.

Thornton, S. 1997. General Introduction. In K. Gelder and S. Thornton (Eds). The SUbculturers Reader. London and New York, Routledge.

Veblen, T. 1899. The theory of the Leisure Class: An Economic Study of Institutions. New York, Macmillan Company.

Venkatesh, V., Morris, M.G., Davis, G.B., Davis, F.D. 2003. User acceptance of information technology: toward a unified view. MIS Quarterly, 27(3), 425-478.

Vroom, V.H. 1964. Work and Motivation. New York, NY, Wiley.

Wu, L.H., Wu, L.C., Chang, S.C. 2016. Exploring consumers' intention to accept smartwatch. Computers in Human Behavior, 64, 383-392.

Zorn, S., Jarvis, W., Bellman, S. 2010. Attitudinal perspectives for predicting churn. Journal of Research in Interactive Marketing, 4(2), 157-169. 